NBER WORKING PAPER SERIES

\title{
REAL OUTPUT IN MENTAL HEALTH CARE DURING THE 1990s
}

\author{
Ernst R. Berndt \\ Alisa B. Busch \\ Richard G. Frank \\ Sharon-Lise Normand \\ Working Paper 11557 \\ http://www.nber.org/papers/w11557
}

\section{NATIONAL BUREAU OF ECONOMIC RESEARCH \\ 1050 Massachusetts Avenue \\ Cambridge, MA 02138}

August 2005

We gratefully acknowledge grant support from NIMH grant R01MH62028 and academic institutional support from the MIT Sloan School of Management. An earlier version of this paper was presented at the Twelfth NUMH Biennial Research Conference on the Economics of Mental Health, Washington DC, September 27-28, 2004. The views expressed herein are those of the author(s) and do not necessarily reflect the views of the National Bureau of Economic Research.

(C2005 by Ernst R. Berndt, Alisa B. Busch, Richard G. Frank and Sharon-Lise Normand. All rights reserved. Short sections of text, not to exceed two paragraphs, may be quoted without explicit permission provided that full credit, including () notice, is given to the source. 
Real Output in Mental Health Care During the 1990s

Ernst R. Berndt, Alisa B. Busch, Richard G. Frank and Sharon-Lise Normand

NBER Working Paper No. 11557

August 2005

JEL No. I10, C43, O33

\section{$\underline{\text { ABSTRACT }}$}

Health accounts document changes over time in the level and composition of health spending. There

has been a continued evolution in the ability to track such outlays. Less rapid has been the ability to interpret changes in spending. In this paper we apply quality adjusted price indexes for several major mental disorders to national mental health account estimates to assess changes in real "output". We show that using the new price indexes reveals large gains in real output relative to application of BLS indexes.

Ernst R. Berndt

Sloan School of Management

MIT, E52-452

50 Memorial Drive

Cambridge, MA 02142

and NBER

eberndt@mit.edu

Alisa B. Busch

Mclean Hospital

$\mathrm{Ph} \mathrm{302 \textrm {a }}$

115 Mill St

Belmont, MA 02478

abusch@hcp.med.harvard.edu
Richard Frank

Department of Health Care Policy

Harvard Medical School

180 Longwood Avenue

Boston, MA 02115

and NBER

frank@hcp.med.harvard.edu

Sharon-Lise Normand

Harvard Medical School

Health Care Policy

180 Longwood Ave

Boston, MA 02115

sharon@hcp.med.harvard.edu 


\section{INTRODUCTION}

During times when mental health spending was increasing, a common perception from observers was that such increases in mental health spending largely reflected rising provider prices. ${ }^{1}$ Others have argued that spending increases manifested a moral hazard response to insurance coverage and instead represented increased use of marginally effective services, with a substantial portion of moneys spent on mental health care providing low value to payers. ${ }^{2}$ In contrast, recent data showing that mental health spending grew at $5.7 \%$ per year between 1991 and 2001 versus a comparable $6.5 \%$ annual growth rate for all of health care has led advocates to worry that these differences in spending growth represent diminished availability and access to care. ${ }^{3}$

In the United States' economic statistical system of National Income and Product Accounts, it is of course conventional practice to view expenditures as the product of price times quantity. ${ }^{4}$ How one interprets changes in health care spending over the last decade therefore depends critically on the extent to which the spending changes are driven by price change, quantity change, quality change, or some combination of these.

One of the factors complicating the interpretation of spending trends is the introduction of new treatments. Pharmacological innovations, such as the selective serotonin reuptake inhibitors ("SSRIs") and the serotonin-norepinephrine reuptake inhibitors ("SNRIs"), have become common in the treatment of depression, and more recently, of anxiety. Other pharmacological innovations include atypical antipsychotics for the treatment of schizophrenia and for bipolar disorder. Significant changes have occurred in other aspects of treatment, such as the development, publication and wide dissemination of treatment guidelines for specialists and primary care physicians, disease 
management programs, and increased use of specialty mental health behavioral carveouts. Concepts of "price", "quantity" and "quality" require careful exploration in the context of a diverse and rapidly changing technology and delivery system that does not produce an easily countable "output".

Our goal in this paper is to offer an initial effort to decompose spending changes for mental health care in the US between 1992 and 1997 into separate price and quantity components, controlling for changes in quality. We disaggregate total mental health spending into treatment of five groups of disorders: anxiety, schizophrenia, bipolar disorders, major depressive disorders, and all other. We then utilize price indexes we have constructed in earlier research, to convert data on nominal national mental health spending into measures of real output change.

We find that while use of published medical care price deflators from the US Bureau of Labor Statistics Consumer Price Index or Producer Price Index results in real output growth of mental health services between 1992 and 1997 of $16 \%$ to 17\%, use of the episode-based price indexes that we have constructed results in much greater real output growth over the same time period, ranging between $70 \%$ and $75 \%$.

After explaining the basic mechanisms of how price indexes are applied to National Income and Product Accounts, we review innovations in measuring prices, quantity and quality for the purposes of constructing price indexes for mental health care. We then present and compare estimates of real output growth for mental health care using traditional indexes and those based on the new learning. 


\section{THE BASICS OF DEFLATION IN THE NATIONAL INCOME AND PRODUCT ACCOUNTS}

US medical care expenditures estimates are published in the National Income and Product Accounts ("NIPA") of the Bureau of Economic Analysis ("BEA"), and in the National Health Accounts ("NHA") of the Centers for Medicare and Medicaid Services

("CMS"). ${ }^{5}$ CMS provides the frequently cited statistic that the US spends about oneseventh of its gross domestic product on medical care, the highest percentage in the world.

Medical care expenditures are usefully interpreted as being the product of a series of prices and quantities. In the language of national income accounting, the quantity of medical care is called "real" medical care expenditures. Moreover, real medical care expenditures can be interpreted as both the output of the medical care services sector and as the consumption of medical care services by American residents.

Within the national accounts, the BEA estimates real medical care expenditures by removing estimated medical inflation from the change in measured expenditures on medical care. This process is known as "deflation". In essence, any increase in medical care expenditures that is not due to price changes is an increase in the quantity of health care, where the quantity includes both changes in the number of treatments and changes in the quality or effectiveness of treatments.

Consider prices of i distinct medical services in time periods 1 and 2 , denoted $\mathrm{p}_{\mathrm{i} 1}$ and $\mathrm{p}_{\mathrm{i} 2}$, respectively, and let their corresponding quantities in time periods 1 and 2 be $\mathrm{q}_{\mathrm{i} 1}$ and $\mathrm{q}_{\mathrm{i} 2}$. Define total expenditures or spending in time periods 1 and 2 as:

$$
\mathrm{S}_{1}=\Sigma \mathrm{p}_{\mathrm{i} 1} \mathrm{q}_{\mathrm{i} 1} \text {, and } \mathrm{S}_{2}=\Sigma \mathrm{p}_{\mathrm{i} 2} \mathrm{q}_{\mathrm{i} 2} \text {. }
$$


The traditional deflation methodology converts the nominal total spending ratio $S_{2} / S_{1}$ into real expenditures or a real output ratio simply by dividing the spending ratio by the ratio of aggregate price indexes, i.e., the real output in period 2 relative to period $1, Q_{2} / Q_{1}$, is computed as:

$$
\mathrm{Q}_{2} / \mathrm{Q}_{1}=\left(\mathrm{S}_{2} / \mathrm{S}_{1}\right) /\left(\mathrm{P}_{1} / \mathrm{P}_{2}\right)
$$

This approach depends critically on the reliability of the price index deflators $\mathrm{P}_{1}$ and $\mathrm{P}_{2}$, and in particular on the ratio $\mathrm{P}_{1} / \mathrm{P}_{2}$. Any error in the price index ratio that measures medical inflation creates an equal error of the opposite sign in the real expenditure ratio, or relative quantity data. Thus there are at least two reasons why price indexes for medical care are important: (i) they measure medical care inflation; and (ii) they are used to derive measures of medical care real expenditures or real output.

Although the U.S. Bureau of Labor Statistics (BLS) has made significant efforts to improve the reliability of its medical care related price indexes, particularly since 1997, many observers believe that the BLS' estimates of price inflation for medical care continue to be upward biased, for at least three reasons: (i) the set of medical care goods and services that are sampled by the BLS is typically updated only infrequently, in the process failing to capture the diffusion of new medical care practices and treatments, and most importantly, pricing medical inputs rather than episodes of care; ${ }^{6}$ (ii) as recent BLS-sponsored research has shown, prices sampled at hospitals and pharmacies tend to be "list" or "official" prices, rather than actual transactions prices negotiated with third party payers ${ }^{7}$ and (iii) measures of price change fail to take into account fully associated quality changes. ${ }^{8}$ If quality has been improving and managed care organizations negotiate 
for significant discounts off of list prices, then price indexes from the 1990s may be biased upwards. Technological change could affect the price index in either direction.

A considerable amount of research in recent years has focused precisely on the issue of obtaining measures of medical care price inflation that to some extent at least incorporate attempts to capture the impact of quality changes. This new research attempts to construct price indexes for medical care in a way that is fundamentally different from prior methods. Specifically, in this recent research an attempt is made to define units of "output of medical care" that reflects the changing bundle of inputs that goes into treating an illness. Moreover, output is defined in a manner that can incorporate measures of the quality of treatment. We now briefly summarize that literature, focusing in particular on research involving changing costs of treating mental health disorders. Most of that work involved some subset of the authors of this paper.

\section{RECENT RESEARCH ON PRICE INDEXES FOR THE TREATMENT}

\section{OF MENTAL HEALTH DISORDERS}

Recent research has examined trends in the direct medical costs of treating three common mental disorders in the U.S.: (i) the acute (16-week) phase treatment of major depressive disorder, based on data from 1991-1996; (ii) the ongoing treatment of schizophrenia, using data from fiscal years 1994 through 2000; and (iii) the ongoing treatment of bipolar I disorders over the 1991-1995 time frame. These three studies cover various spans of years during the decade from 1991 through 2000. These treatments also vary in how they are funded: the schizophrenia treatment cost data derive from public sector funding through Medicaid, while data for the treatment of the major depressive and bipolar I disorders are taken from private sector third party payers. ${ }^{9}$ 
The general methodology used in this line of research that distinguishes it from prior work on medical price indexes concerns the approach to measuring quantity and quality of treatment. The approach to defining output taken by the BLS focuses on specific services used in the treatment of disease as measures of "output". That is, in the case of mental health care, outputs would be defined as physician visits, inpatient hospital stays, and prescriptions for psychotropic medications. In our view these are inputs in treatment of diseases. We view output as a "course of treatment" over a specified time period. Treatments for most mental disorders consist of combining a number of treatment inputs. For example, in treatment of depression it is common to use combinations of physicians' visits for assessment and medical management, antidepressant medication, and psychotherapy. These combinations of inputs are designed to be administered over periods ranging from 12 weeks to 16 weeks in the acute phase and for up to eight months in the continuation phase of treatment. Thus the treatment that produces health benefits is not a visit or a prescription, but combinations of these inputs over time. Thus for all three of the major illnesses discussed below, "output" is defined in terms of combinations of inputs over time. For depression we focus on the acute phase of treatment, a period of 16 weeks. For bipolar disorder and schizophrenia that are most frequently viewed as severe and persistent or chronic mental illnesses, we define output as combinations of treatment inputs over a year.

There are important implications that stem from defining "output" in this way. The first is that defining output in a way that accords with how clinical science defines and tests treatment technologies, makes it possible to use clinical research to define the quality of a course of treatment, in terms of the impact on symptoms and functioning. A 
second important implication of defining output as bundles of inputs for a specified time period is that substitution among inputs is possible. That is, our approach may allow for a particular level of health improvement for depression to be reached by either administering 12 visits of psychotherapy over a 16 week period or by prescribing four months of an antidepressant at an appropriate dose along with eight medication management visits. In addition, as the quality of different inputs changes over time, due to technological advances, the degree of substitution in production might also change. To the extent that changes take place over time in the composition of treatments, input costs and episode treatment costs need not move in the same direction. Our approach to defining quality allows for such input compositional change whereas the BLS approach has a far more limited ability to do so.

The second main feature of the new research on price indexes in mental health is that these indexes each are constructed using information on the quality of each treatment based on incorporating combinations of clinical research and expert clinical opinion. Each of the three indexes does so in a somewhat different fashion. In each case clinical research findings are utilized that compare treatment technologies corresponding to our "output" measures; this clinical research has generated practice guidelines published by the American Psychiatric Association, as well as leading research efforts (the schizophrenia Patient Outcomes Research Team), and the federal government. This clinically-based information is used to create quality indicators for each of the courses of treatment identified in administrative claims data. Use of this information permits us to construct quality-adjusted price indexes for courses of treatment for major depression, schizophrenia and bipolar disorder. 


\section{A. Price Indexes for the Treatment of Acute Phase Major Depressive Disorder}

Using the combination of retrospective medical claims actual transactions cost data from Medstat's publicly available MarketScan database, along with clinical literature and expert clinical opinion, recently Berndt et al. reported results of a study examining changes over time in the costs of treating an episode of acute phase major depressive disorder. ${ }^{10}$ The study focused on changes in spending to treat an episode of depression, particularly that associated with changing bundles of inputs, thereby accounting for substitution among treatment inputs. For example, even though both the per session costs of psychotherapy and the costs of prescriptions for antidepressant pharmaceuticals may be increasing over time, to the extent higher cost psychotherapy sessions are substituted by increased use of lower cost antidepressant pharmaceuticals, it is possible that this "substitution offset" compositional change results in net lower total episode treatment costs. In contrast, the BLS' fixed input bundle approach fails to incorporate the potential for such substitutability among treatment inputs.

Using retrospective medical claims data from four large self-insured employers offering more than 25 health plans to an annual average of about 425,000 employees and their dependents, approximately 13,000 acute phase episodes of major depressive disorder were identified over the 1991-1996 time period. For each of these episodes, all ambulatory claims associated with either single or recurrent episodes of depression, as defined by ICD-9 primary diagnostic codes 296.2x or 296.3x, were identified. Episodes of care were constructed that included all treatments given in the 16 weeks following initiation of care for depression, with distinct episodes defined in terms of eight or more weeks of gaps in care. 
To rate outcomes from treatment that are not directly observable in retrospective claims data, the authors used existing medical literature as an evidentiary platform, and combined it with expert judgment to estimate expected outcomes. More specifically, about 200 alternative treatment/patient type cells were identified in the retrospective medical claims database. An example of a treatment/patient type cell is a woman, age 18-45, having no medical comorbidity, no history of recent substance abuse, treated with an SSRI for more than 60 days, also having three or more psychotherapy visits, treated in a specialty mental health treatment setting, for 16 weeks. The expert panel was asked to rate the likelihood that patients in each cell would achieve either full remission or a partial remission from their depression.

This process yielded expected outcomes data for treatment cells commonly observed in the Medstat database. Health care spending for each of the elements of treatment for depression (all payments made by the insurer to the provider, plus any costsharing assigned to the patient, such as out of pocket copayments for psychotherapy or prescription drugs) were summed into a nominal dollar total for each treatment episode. The episodes were then classified as falling into various distinct treatment bundles.

Very substantial changes in the composition of treatment for acute phase major depression took place in the first half of the 1990s, following the introduction of fluoxetine, the first SSRI, in 1988, sertraline, the second SSRI in 1992, and paroxetine in 1993. The largest shift involved reduction in psychotherapy alone, from about $41 \%$ of episodes treated in 1991, to about $27 \%$ in 1995 . During the same time interval, the combination treatment of SSRIs and psychotherapy doubled, from $23 \%$ to $48 \%$. Solo therapy involving only the older generation antidepressant tricyclics ("TCAs") declined 
from about 7\% to around 2\% between 1991 and 1995 . Hence, in the relatively short time frame involving only five years in the early 1990s, a very dramatic shift in the composition of treatments for depression took place, primarily involving substitution against psychotherapy only and either TCA only or TCA in combination with psychotherapy, and instead moving primarily toward SSRI plus psychotherapy combination treatment, or SSRI only therapy.

This change in composition of treatments had a significant impact on the average cost of treating an episode of acute phase major depression. In this and several related studies, the researchers computed price indexes in a variety of ways. ${ }^{11}$ The preferred calculation, based on a multivariate regression model with the logarithm of direct medical costs as the dependent variable, and with patient characteristics, expected outcome (from the expert panel rating), and yearly indicator variables as explanatory variables, yielded a time series of price (or cost) indexes for expected full and for expected partial remissions. Both price indexes fell from a base year index value of 100 in 1991 to about 88 in 1995, implying a cumulative price decline of about $12 \%$, and an average annual growth rate of $-2.7 \%$.

By comparison, between 1993 and 1996 the BLS PPI for medical services increased 8\%, that for psychiatric hospitals rose about 10\% between 1992 and 1996, while that for psychotropic drugs increased by $21 \%$ between 1991 and 1996 . Why the difference, and which set of price trends should one find most credible?

For present purposes, it is sufficient to note that the BLS price indexes are based on the assumption that the composition of treatment bundles is fixed. An implication is that these price index calculations by the BLS do not permit substitution over time in the 
way a medical condition such as depression is treated. In particular, although the shift away from psychotherapy-intensive to SSRI-intensive treatment bundles was in fact dramatic, such compositional shifts are not incorporated in the BLS' medical care price indexes. It is here that the definition of output as a course of treatment for a specified time period is most important and where it emerges as the source of differences between the BLS indexes and the ones we constructed.

Concerning quality of care, although measurement of quality based on medical claims data has well-known shortcomings, one can nonetheless obtain some notion of quality change by tracing the proportion of observed episodes receiving treatment that

met the Agency for Health Care Policy Research guidelines for care. In the Medstat data, the proportion meeting treatment guideline standards was $42 \%$ in $1991-1992$, jumped to 53\% and 54\% in 1993 and 1994, and then fell slightly to 51\% in 1996 and $49 \%$ in 1996.

In summary, for acute phase depression, not only did average treatment quality increase as evidenced by the increase from $42 \%$ to $49 \%$ of treated episodes meeting guideline standards, but controlling for expected outcomes, between 1991 and 1996 the average costs of attaining expected full and partial remissions declined by about $12 \%$. This achievement occurred in large part due to the substitution away from more costly psychotherapy-intensive treatment to less costly psychopharmacologic treatment involving either psychotherapy in combination with SSRIs, or SSRI-only treatment.

\section{B. Price Indexes for the Ongoing Treatment of Schizophrenia}

In a recent article, Frank, Berndt, Busch and Lehman analyze retrospective mental health-related Medicaid medical claims data from two counties in Florida containing the cities of Jacksonville and Orlando, over six fiscal years, between 1994 and 2000, 
involving treatment of patients with schizophrenia. ${ }^{12}$ These claims data included inpatient and outpatient procedure codes, pharmacy data, mental health-related diagnoses, and the timing of any services. The setting was a lightly managed fee-for-service environment, where primary care physicians received a capitation payment for providing case management and gate keeping services, but where mental health services were not carved out.

The study constructed price indexes for treatment of schizophrenia. Because schizophrenia is a severe and persistent mental disorder, output was defined as the course of treatment over an entire year. Using the Patient Outcomes Research Team ("PORT") treatment recommendations as a basic framework for classifying observed treatment bundles and quality of care, Frank et al. identified treatment bundles whose quality was evidence-supported (e.g., various pharmacotherapy-psychosocial treatment combinations), was evidence-equivocal (e.g., vocational rehabilitation), and for which there was no supporting evidence (e.g., only individual or group therapy without any antipsychotic pharmacotherapy, or only pharmacotherapy without any psychosocial supportive or psychotherapies). ${ }^{13}$ These quality measures clearly reflect what was necessary to meet minimal standards of care identified in the PORT study. While the quality of care indicators do not assess whether the patient received adequate medication doses for adequate durations, or adequate type and number of psychotherapy sessions, using this rather simple set of indicators of evidence-based treatment provides the basis for documenting large variations in quality.

Frank et al. reported results of estimated multivariate regression models with the logarithm of annual mental health spending as the dependent variable, nine solo and 
combination treatment bundle types as indicator explanatory variables, and additional indicator variables reflecting patient histories. A variety of price indexes was calculated, using alternative annual treatment/patient distributions as either fixed or varying over the six fiscal years. The preferred price index reveals an average price decline of about $5.5 \%$ annually, and corresponds with a cumulative decline of about 25\% between 1994 and 2000.

In summary, analogous to the treatment of depression, for schizophrenia Frank et al. find that compositional changes in the treatment of schizophrenia have been dramatic, with pharmacologic treatment moving towards increased use of the newer atypical antipsychotics, and with decreased intensity in the use of various forms of psychosocial therapy. Although the quality of care data for schizophrenia are less detailed than that for treatment of acute phase depression, Frank et al. report that it appears that an increasing proportion of patients with schizophrenia are receiving treatment that is not supported by the clinical evidence. Nonetheless, holding quality of care approximately constant, the annualized treatment costs for the ongoing treatment of schizophrenia are falling approximately 5.5\% per year. While the cumulative decline is about $25 \%$ over the 1994 through 2000-time period, most of this decline appears to have occurred in the first half of this six-year time interval.

\section{Treatment Price Indexes for Bipolar Disorder: Preliminary Findings}

Ling, Busch and Frank have reported preliminary research findings examining changes over time in the costs of treating bipolar I disorder. ${ }^{14}$ They employ Medstat's 1991-1995 non-capitated database, and include in their sample patients 18-64 years old upon enrollment who were diagnosed with bipolar I disorder; patients also diagnosed 
with schizophrenia were excluded. This gave them a sample of 3,767 person years, or about 753 per year, comprising an unbalanced panel of 1851 distinct individuals.

Ling et al. identified four mutually exclusive and exhaustive treatment bundles: (i) no treatment - no mood stabilizers, no psychotherapy, and no antidepressants - this bundle fell from about 8\% of observed person-years in 1991 to $6 \%$ in 1995; (ii) solo treatment with psychotherapy but no mood stabilizers - this bundle increased slightly from $28 \%$ to $31 \%$ of cases between 1991 and 1995; (iii) solo treatment on at least one mood stabilizer but no psychotherapy - this bundle increased from about $9 \%$ of cases in 1991 to $11 \%$ in 1995; and finally, (iv) at least one mood stabilizer and psychotherapy this bundle fell from $56 \%$ to $51 \%$ of cases observed between 1991 and 1995. Bundles (iii) and (iv) are included in guideline treatment recommendations. ${ }^{15}$ Notably, the mean number of psychotherapy visits increased from 7.9 in 1991 to 10.4 in 1995, while the proportion of patients having at least one psychotherapy visit was stable at $83 \%$.

Compared to the relatively dramatic compositional changes in type of treatment for depression and schizophrenia, for bipolar I disorders this change in treatment, at least over the 1991-1995 time period, was not as dramatic. Using a multivariate regression specification similar to that in the Frank et al. analysis that included indicator variables for treatment type, controlled for other patient characteristics, and allowed parameters to vary by year, Ling et al. report that the estimated cost index declined by about $15 \%$ between 1991 and 1995, although it initially increased by 11\% between 1991 and 1992 . The entire reduction occured in the last three years, with particularly large declines in 1993 and 1995. Averaged over the five years, the mean rate of price decline is 3.3\% per annum. 


\section{CONSTRUCTION OF AN OVERALL PRICE INDEX FOR MENTAL}

\section{HEALTH}

Having reviewed recent research that reports quality-constant or quality-adjusted price indexes for the treatment of selected mental disorders, we now outline how we construct alternative price indexes aggregated over the various mental disorders. Our goal is to use this aggregate price index to deflate nominal 1997 U.S. total mental health expenditures, and then to convert it into real expenditures in 1992 dollars.

Table 1

Illness Decomposition of National Mental Health Spending (millions \$)*

\begin{tabular}{|l|c|c|}
\hline & $\mathbf{1 9 9 2}$ & $\mathbf{1 9 9 7}$ \\
\hline Anxiety & 9,001 & 11,969 \\
\hline Schizophrenia & 14,247 & 18,944 \\
\hline Affective & 15,848 & 21,074 \\
\hline Bipolar & 6,656 & 8,851 \\
\hline Depression & 9,192 & 12,223 \\
\hline Other & 16,124 & 21,441 \\
\hline TOTAL & $\mathbf{5 5 , 2 2 1}$ & $\mathbf{7 3 , 4 2 7}$ \\
\hline
\end{tabular}

* Numbers may not add up due to rounding

As is shown in Table 1, from SAMSHA we observe that total nominal mental health spending in 1992 was about $\$ 55.221$ billion, while from the CMS Health Accounts the comparable spending amount for 1997 is $\$ 73.427$ billion. $^{16}$ In order to allocate total mental health care spending into expenditures for specific mental disorders, we employ as weights the disease-specific values reported by Rice for 1994; these weights are $16.3 \%$ for anxiety, $25.8 \%$ for schizophrenia, $28.7 \%$ for affective disorders (including both depression and bipolar disorders), and $29.2 \%$ for all others. ${ }^{17}$ The "all others" category includes primarily cognitive disorders and psychoses. We apply these weights to 
disaggregate total mental health spending in 1992 and 1997; results are given in Table 1. In order to decompose affective disorders into depression and bipolar disorders, we note that the prevalence (incidence times duration) for mania is about $42 \%$ of all affective disorders. ${ }^{18}$ Applying this $42 \%$ proportion to the $28.7 \%$ aggregate affective disorder expenditure weight yields weights of about $12 \%$ (42\% of $28.7 \%$ ) to bipolar, and $16.7 \%$ (58\% of $28.7 \%$ ) to depression. Using these constant weights, we decompose 1992 and 1997 nominal national total mental health spending into disease-specific expenditures; results are given in Table 1.

We are not aware of any research to date that focuses on measuring a price index for the treatment of anxiety. Since the treatment of anxiety typically involves use of the SSRIs, as in the treatment of depression, we assume the price index for anxiety moves at the same rate as that for depression; this assumption is further supported by the fact that anxiety and depression are frequently comorbid illnesses. For the "all other" category, since treatment typically involves use of the atypical antipsychotic medications, we assume that prices for the treatment of the cognitive disorders and psychoses move at the same rate as those estimated for the treatment of schizophrenia. Hence the schizophrenia price index will be applied to $55 \%$ of the nominal spending $(25.8 \%+29.2 \%)$.

Recall that the depression price index we constructed covered the years 1991 through 1996, that for schizophrenia fiscal years 1994 through 2000, and that for bipolar I disorder 1991 through 1995. In order to convert 1992 and 1997 nominal expenditures into real magnitudes, it is necessary to extend the depression price index beyond 1996 to 1997, that for bipolar I disorder beyond 1995 to 1996 and 1997, and that for bipolar 
disorders back from 1994 to 1993 and 1992. This therefore requires extrapolation, both forward and backward in time.

Table 2

Laspeyres Producer Price Indexes

(Base Year 1992)

\begin{tabular}{|l|c|c|c|c|c|c|}
\hline & $\mathbf{1 9 9 2}$ & $\mathbf{1 9 9 3}$ & $\mathbf{1 9 9 4}$ & $\mathbf{1 9 9 5}$ & $\mathbf{1 9 9 6}$ & $\mathbf{1 9 9 7}$ \\
\hline Depression & 100 & 103.5 & 101.5 & 94.6 & 93.4 & $91.2^{*}$ \\
\hline Bipolar & 100 & 101.5 & 87.4 & 79.7 & $79.7^{* *}$ & $79.7^{* *}$ \\
\hline Schizophrenia & 100 & $94.8 \dagger$ & 89.8 & 77.2 & 68.7 & 66.0 \\
\hline Schiz. Alt & 100 & $100 \dagger \dagger$ & $100 \dagger \dagger$ & 85.9 & 76.5 & 73.5 \\
\hline $\begin{array}{l}\text { BLS CPI } \\
\text { MED }\end{array}$ & 100 & 102.8 & 105.7 & 108.6 & 111.4 & 114.3 \\
\hline BLS PPI MD & 100 & 105.3 & 108.0 & 111.9 & 112.0 & 113.4 \\
\hline
\end{tabular}

* Linear extrapolation from previous year

** Estimates based on 1999data showing flat index

† Linear extrapolation of 7 year trend 1994-2001

†† Assumes flat index based on no drug innovation and flat Medicaid expenditure shares in aggregate

As seen in Table 2, for depression we linearly extrapolate to 1997. For the bipolar disorders, when treatment patterns were compared between 1995 and 1999 we observed that little change had occurred. This suggests that assuming a flat index would be conservative with respect to estimating output growth. We therefore assume that the price index for bipolar disorder in 1996 and 1997 was unchanged from its 1995 value. For schizophrenia, we make two alternative assumptions regarding backward extrapolation from 1994 to 1993 and 1992. First, we implement a linear extrapolation back to 1992 and 1993 from the seven-year trend estimated for fiscal years between 1994/1995 and 1999/2000. As an alternative, we assume no drug or other treatment innovations, and hold constant the 1992 and 1993 schizophrenia treatment price index at 
its 1994 value. The resulting price indexes, all normalized to 100 in the 1992 base year, are presented in Table 2.

For purposes of comparison, we also present the BLS's Consumer Price Index for Medical Care (“BLS CPI MED”), and its Producer Price Index for Physicians' Office Visits ("BLS PPI MD"). Differences in time trends between the BLS's price indexes and those estimated based on retrospective medical claims data holding quality of care constant (bipolar and schizophrenia), or adjusting for expected outcome (depression) are surprisingly dramatic. While the BLS's price indexes increase by 13-14\% between 1992 and 1997, the alternative price index for depression declines 13\%, that for bipolar disorders declines by $20 \%$, and those for schizophrenia fall by between $26 \%$ and $34 \%$. These are very large differences that have important implications for the interpretation of changes over time in mental health spending.

To quantify the implications of differences in price indexes, we deflate 1997 nominal expenditures, by mental disorder, into real expenditures or real output by dividing the 1997 expenditures (in Table 1) by the disease-specific price indexes (in Table 2); for purposes of comparison, we also deflate using the BLS price indexes. We then take the ratio of real output in 1997 to that in 1992 (“ $\Delta$ Q97-92”); results are given in Table 3. 
Table 3

Disaggregated Output Change Estimates

\begin{tabular}{|l|l|c|}
\hline \multicolumn{1}{|c|}{ Illness } & $\Delta$ Q97-92 \\
\hline 1. & Anxiety & 1.46 \\
\hline & MDD & 1.16 \\
\hline & BLS CPI MED & \\
\hline 2. & Schizophrenia & 2.01 \\
\hline & Linear & 1.81 \\
\hline 3. & Flat & 1.67 \\
\hline & Affective & 1.46 \\
\hline & Bipolar & 1.82 \\
\hline 4. & MDD & 1.16 \\
\hline & Other & 1.18 \\
\hline & Schizo Alternative & \\
\hline & BLS CPI MED & \\
\hline & BLS PPI MD & \\
\hline
\end{tabular}

For anxiety, use of the (depression) treatment price index as a deflator results in 1997 real output being $46 \%$ greater than in 1992, whereas with the BLS Medical Care Consumer Price Index, this real output growth is much smaller, only 16\% between 1992 and 1997. For schizophrenia, use of the backwards extrapolated schizophrenia treatment price index to 1992 results in 1997 real output being $101 \%$ larger than in 1992, whereas if one makes the more conservative assumption that there was no change between 1992 and 1994 in the treatment price index for schizophrenia, the real output growth in treating schizophrenia increases by a smaller but still very substantial $81 \%$.

In terms of the affective disorders, for the treatment of major depressive disorders real output has grown 46\% between 1992 and 1997, whereas for providers of services for the treatment of bipolar I disorders, real output growth has been 67\%; each of these is based on the treatment price indexes that take into account the changing composition of treatments over time. Finally, for the all other mental illness treatment category, when 
one employs the conservative "flat" schizophrenia price index (assuming no changes between 1992 and 1994), real output growth from those providing ongoing treatment of schizophrenia has increased by $82 \%$ between 1992 and 1997, whereas if one instead employs the BLS's Medical Care Consumer Price Index, this increase would be considerably smaller at $16 \%$. Using the physician PPI yields a quantity increase of $18 \%$.

Finally, in order to obtain a measure of the overall growth in output of services from mental health providers between 1992 and 1997, we weight the various measures of disease-specific real output growth by the constant 1994 direct medical care shares reported by Rice [1997], which are implicit in Table 1. Alternative estimates of this growth in real aggregate output of mental health services are presented in Table 4.

Table 4

Alternative Estimates of Aggregate Mental Health Services Output Change

\begin{tabular}{|l|l|}
\hline & $\mathbf{\Delta Q 9 7 - 9 2}$ \\
\hline Mental Health Indexes & \\
\hline Linear Schizophrenia & 1.70 \\
\hline Flat Schizophrenia & 1.66 \\
\hline $\begin{array}{l}\text { Mix Mental Health/CPI (Flat } \\
\text { Schizophrenia) }\end{array}$ & 1.39 \\
\hline BLS CPI MED & 1.16 \\
\hline BLS PPI MD & 1.17 \\
\hline
\end{tabular}

The striking conclusion that emerges from Table 4 is that when one employs treatment price indexes that allow for compositional changes in treatment bundles, and when one holds quality of care approximately constant, real output growth from providers of mental health services has increased by $66 \%$ to $70 \%$ between 1992 and 1997, depending on whether one extrapolates backward in time, or holds flat the 1992 schizophrenia treatment price index relative to its 1994 value. By contrast, use of the 
BLS's Medical Care price indexes as deflators yields only about one quarter as large an estimate of the real output growth, $16 \%$ with the Medical Care consumer price index and 17\% with the Physician Office producer price index.

Using an aggregate index that uses a CPI for anxiety disorders, the flat schizophrenia extrapolation for schizophrenia, the bipolar and major depressions indexes and the CPI for other mental disorders to deflate the ratio of nominal spending for 1997 and 1992, yields a real output change estimate of 1.39. Thus the conservative lower bound that uses BLS indexes for diseases where no explicit alternative index has been constructed indicates an increase in real output that is roughly double that which would be obtained by simply relying exclusively on the BLS indexes.

\section{DISCUSSION AND SUMMARY}

In this paper we make a first attempt to use recent research on the construction of alternative price indexes for the treatment of mental disorders to assess the aggregate performance of the U.S. mental health delivery system. Recognizing that the task of constructing price indexes for all mental disorders is not complete, we have used existing work in combination with traditional indexes to provide several first order approximations of estimated changes in the real output of the mental health sector. Our estimates highlight the fact that even when the existing indexes are used for only those disorders where an alternative price index has been developed, estimates of real output growth are more than double the levels obtained from application of BLS price indexes.

One policy implication of this finding relates to concerns about the fact that spending growth for mental health has lagged behind general medical care. Such 
comparisons implicitly use the general medical care spending growth to deflate mental health spending. The evidence to date suggests that for major depression, bipolar disorder and schizophrenia, prices have declined relative to alternative medical price indexes for cardiovascular disease ${ }^{19}$. This means that some in the mental health policy community have been significantly underestimating real output growth in the mental health sector.

A second dimension of economic performance of the mental health sector is related to changes in productivity, which is calculated as the difference between aggregate real output growth minus aggregate real input growth. Our estimates do not provide direct evidence on this issue. However, there are some indirect empirical clues about how productivity changed during the 1990s. To assess multifactor productivity one must first estimate real output growth and then subtract the growth in real inputs from that estimate. Data from insurance claims and reports from analyses of natural experiments during the 1990 s indicate that specialty providers generally have experienced price declines. ${ }^{20}$ This suggests that holding quality of care constant, either providers' have reduced their margins or they are benefiting from productivity gains. In either case real output from providers grew, as did real consumption by patients.

There are several other indicators of changes in real inputs. The number of admissions per patient care staff and the number of days per patient care staff in private psychiatric hospitals increased by about 36\% between 1992 and $1998 .^{21}$ Moreover, the number of psychotherapy visits per episode of depression declined, while the quality of care (as measured by the percentage of episodes meeting guideline standards of care) increased. ${ }^{22}$ At the same time use of prescription drugs to treat major mental disorders has expanded dramatically. Together these data point in the direction of net reductions in 
real inputs per episode of care, holding quality constant. These are however, not systematic assessments and are suggestive and preliminary rather than definitive.

This paper advances a line of research that aims to provide a strong empirical foundation for interpreting regularly collected economic statistics on the mental health sector. To date the interpretation of changes in mental health spending and service utilization has been too frequently left to the eye of the beholder. New research on treatment price indexes for mental disorders is beginning to offer a method of more clearly assessing the performance of the mental health delivery system based on data from national health accounts. The results presented here are first approximations of changes in real output. The important lesson from this exercise is that real output in mental health care has increased far more than is apparent based on use of BLS price indexes or on simple comparisons to health sector spending changes over time.

\footnotetext{
${ }^{1}$ McKusick DT, Mark TL, King E, Harwood R, Buck JA, Dilonardo J, Genuardi JS. Spending for mental health and substance abuse treatment, 1996. Health Affairs. 1996;17(5):147157.

${ }^{2}$ See, for example, Duggan MG. Does Medicaid pay too much for prescription drugs? A case study of atypical antipsychotics. Journal of Health Economics, 24(1):1-31, 2005; and Croghan TW. The controversy of increased spending for antidepressants. Health Affairs. 2001;20(2):129-135.

${ }^{3}$ Mark T., R.M. Coffey, D McKusick et al National Expenditures for Mental Health Services and Substance Abuse Treatment 1991-2001, SAMHSA Publication SMA 04-3999, Rockville MD: SAMHSA, 2005; Hanson KL. Public opinion and the mental health parity debate. Lessons from the survey literature. Psychiatric Services. 1998;49(8):1-59-1066.

${ }^{4}$ Triplett JE, Berndt ER. Introduction: New Developments in Measuring Medical Care. In Triplett JE and Berndt ER, Measuring the Prices of Medical Treatments. Washington DC: Brookings Institution Press, 1999:1-33.

${ }^{5}$ Much of the material in this section is taken from Triplett and Berndt, supra.

${ }^{6}$ For a recent discussion, see The special case of medical services, ch. 6 in National Research Council, At What Price: Conceptualizing and Measuring Cost-of-Living and Price Indexes, Panel on Conceptual, Measurement and Other Statistical Issues in Developing Cost-of-Living Indexes, Charles L. Schultze and Christopher Mackie, eds., Committee on National Statistics, Division of Behavioral and Social Sciences and Education, Wshington DC: National Academy Press, 2002:178-190.

${ }^{7}$ Song X, Marder WD, Baser O, Houchens R, Conklin JE, and Bradley R. Can health care claims data improve the estimation of the Medical CPI? Paper presented at the National Bureau of Economic Research/Conference on Research in Income and Wealth Conference, Vancouver BC, June 28, 2004; also presented at the National Burau of Research Summer Institute, Health Care Program, August 6, 2004.

${ }^{8}$ See Schultze and Mackie, supra.

${ }^{9}$ Much of the material in this section is taken from Berndt ER. Price indexes for the treatment of mental health disorders, Pharmacoeconomics, 2004;22(Suppl 2):37-50.
} 
${ }^{10}$ Berndt ER, Bir A, Busch SH, Frank RG, Normand S-L. The medical treatment of depression, 19911996. Productive inefficiency, expected outcome variations, and price indexes. Journal of Health Economics. 2002;21:373-396.

${ }^{11}$ Frank RG, Busch SH, Berndt ER. Measuring prices and quantities of treatments for depression. American Economic Review. 1998;88(2):106-111; Frank RG, Berndt ER, Busch SH. Price indexes for the treatment of depression. In Triplett JE ed., Measuring the Prices of Medical Treatments. Washington DC: Brookings Institution Press, 1999:72-102.

${ }^{12}$ Frank RG, Berndt ER, Busch AB, Lehman AF. Quality-constant prices for the ongoing treatment of schizophrenia. An exploratory study. Quarterly Review of Economics and Finance. July 2004;44(3):390409.

${ }^{13}$ Lehman AF. Quality of care in mental health. The case of schizophrenia. Health Affairs. 1999;18(5):52-65; Lehman AF, Steinwachs DS. Translating research into practice. The schizophrenia patient outcomes research team (PORT) recommendations. Schizophrenia Bulletin. 1998;24(1):1-10; Lehman AF, Steinwachs DS and the Survey Co-Investigators of the PORT Project. Patterns of usual care for schizophrenia. Initial results from the schizophrenia patient outcomes research team (PORT) client survey. Schizophrenia Bulletin. 1998;24(1):11-19.

${ }^{14}$ Ling DYC, Busch AB, Frank RG. Treatment price indexes for bipolar disorder . Working paper Harvard Medical School June 2004

${ }^{15}$ American Psychiatric Association. Practice guidelines for the treatment of patients with bipolar disorder (revision). Supplement, American Journal of Psychiatry. 2002;159(4):1-50.

${ }^{16}$ Coffey, R.M. et al National Estimates of Expenditures for Mental Health and Substance Abuse Treatment, 1997 USDHHS, SAMHSA Publication No. SMA-00-3499; Rockville MD: SAMHSA, 2000.

${ }^{17}$ Rice DP. Costs of mental illness. Update estimates. Rockville, MD: SAMSHA, unpublished data, 1997.

${ }^{18}$ Rouse B. (ed), Substance Abuse and Mental Health Statistics Source Book, 1998 Rockville MD:

SAMHSA, 1998

${ }^{19}$ Cutler D.M., M. McClellan, and J.P. Newhouse, "The Costs and Benefits of Intensive Treatment for Cardiovascular Disease" in J.E. Triplett (ed) Measuring the Prices of Medical Treatments, Washington DC: The Brooking Institution Press, 1999.

${ }^{20}$ Frank, RG and JR Lave, "Economics" in S. Feldman (ed) Managed Behavioral Health Services Springfield Il: Charles Thomas Press, 2003

${ }^{21}$ Manderschied RW and MJ Henderson, Mental Health U.S., 2002 DHHS Publication No. (SMA) 3938, Rockville MD: SAMHSA, 2004

${ }^{22}$ Busch, SH, ER Berndt, and RG Frank, "Creating Price Indexes for Measuring Productivity in Mental Health Care" in A Garber (ed) Frontiers of Health Policy Vol 4, Chicago: University of Chicago Press, 2001. 